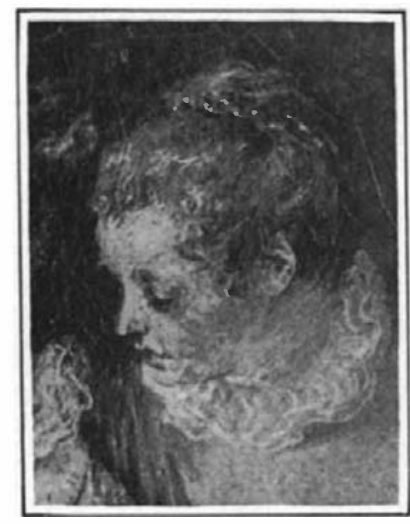

Fig. 1.- Microphotograph of head in a Watteau. No. 55 in Edinburgh National Gallery.

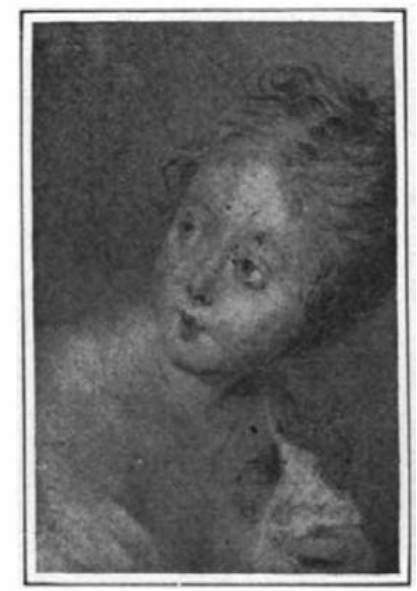

Fig. 3.-Microphotograph of face from a Pater. No. 60 in Edinburgh Collection.

\title{
A New Way of Detecting Art Forgeries
}

The Microphotographic Study of Brushwork

By Prof. A. P. Laurie, Hewitt-Watt College, Edinburgh

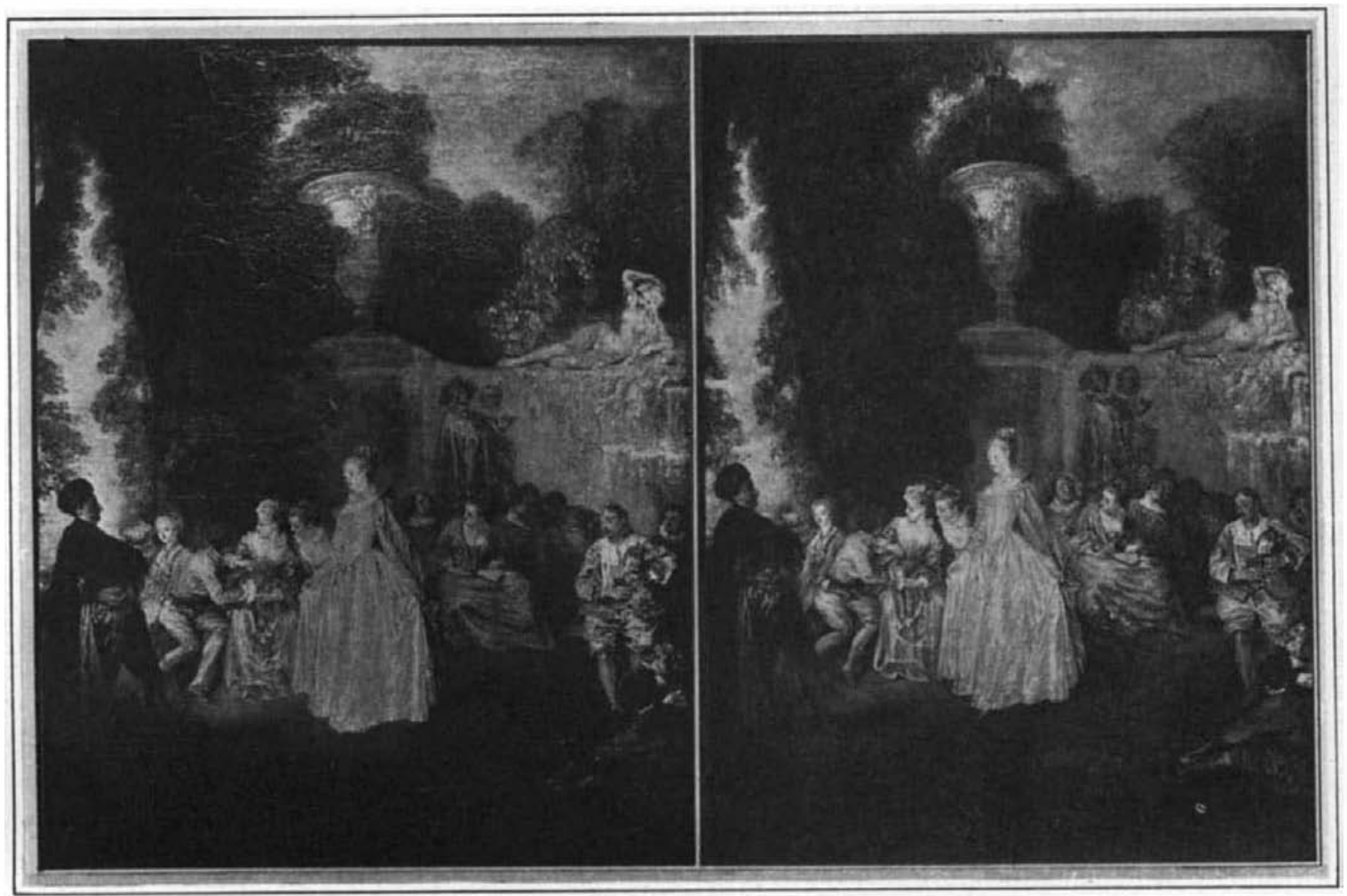

Fig. 4.-A representation of a genuine painting by Watteau. (No. 55 in the National Gallery of Edinburgh.)
Fig. 5.-Copy of the Watteau No. 55, which is apparently handled quite in the manner of the master.

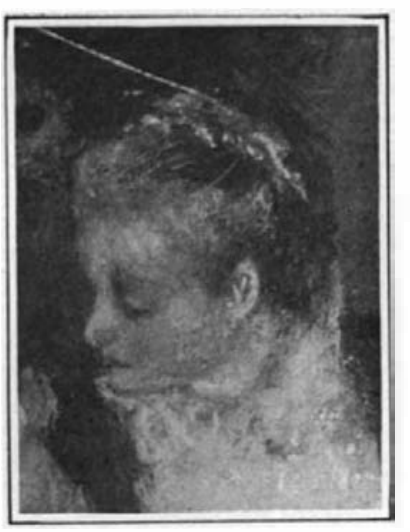

Fig. 2.-Microphotograph of the head shown in Fig. 1 , but from the copy of Watteau shown in Fig. 5 .

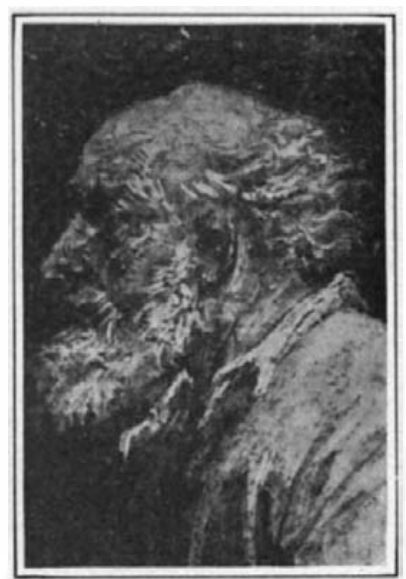

Fig. 6.-Head of old man by Teniers. No. 817 in London National Gallery.
$F^{O R}$ some time $I$ have been engaged in a series of researches, with a view to applying scientific methods to the identification of pictures and the exposure of forgeries. In the first place I began by making a careful investigation into the history of pigments with a view to deciding at what dates certain pigments were used in the history of painting, as it is obvious that if we have a knowledge of this, we can very often approxi mately date a picture, and so decide whether it wa painted at the period to which it has been assigned. These investigations were carried out by the study of dated douments, such as Illuminated Missels, Venetian Duceli, and the Coram Rege Rolls in the Rector London, which are illustrated with miniatures from 1500 to 1700

By means of these dated documents it has been possible to construct a fairly complete history of pigments, and to state very definitely when certain pigments came into use and other pigments ceased to appear upon the artist's palette. In addition, I have devoted considerable attention to the microscopic study ef the cons a view to detudy repainting and identifying the pigments in position and also to the microscopic identification of pigments enabling one to deal with the very tiny samples which can be removed without injury to the picture.

These methods, then, enable one to decide whethe the picture is a modern forgery, whether repainting has taken place, and also to date the picture itself approximately. In addition, it has been found that certain artists are accustomed to use certain pigments, so that he probability of a picture being by a given artist is strengthened if the pigment which he generally used is found upon it It was while making these researches that I was struck with he I was struck with the amount of information which could be derived as to the painting of a picture, from the c a $r$ e u 1 study of the car efu $\mathrm{magn}$ if i ed. It is, of course, customary for eurs to use a magnifying glass, but the information to be obtained is very much more reliable and useful if, instead of us-

ing the magnifying glass, careful microphotographs are taken of selected portions of the picture under examination.

In order to get successful results, the enlarged photograph should be taken directly on to the negative, the amount of enlargement depending on the style of the brushwork of the particular artist. As a rule, about three diameters are sufficient, but there are cases wher enlargements up to as much as six diameters are of value for this purpose. By means of these photograph one is able to isolate the facts of brushwork without any confusing considerations, and one is able to compare side by side a series of such microphotographs.

Supposing, for instance, a picture is believed to be by a given artist, microphotographs of selected portions are taken and these are compared with microphotographs of pictures of undoubted authenticity by the same hand; while, if there is some other artist whose name is suggested as a possible author of the picture microphotographs are also taken of his work, for com parison. In this way it is possible in the case of very large number of painters, to arrive at very definite conclusions. There are schools of painting, of course which do not lend themselves to these methods, but, on the other hand, there are many artists whose individuality of brushwork is so marked and so characteristic as to make imitation impossible. The copyist or the pupil may imitate a master's general style, but each

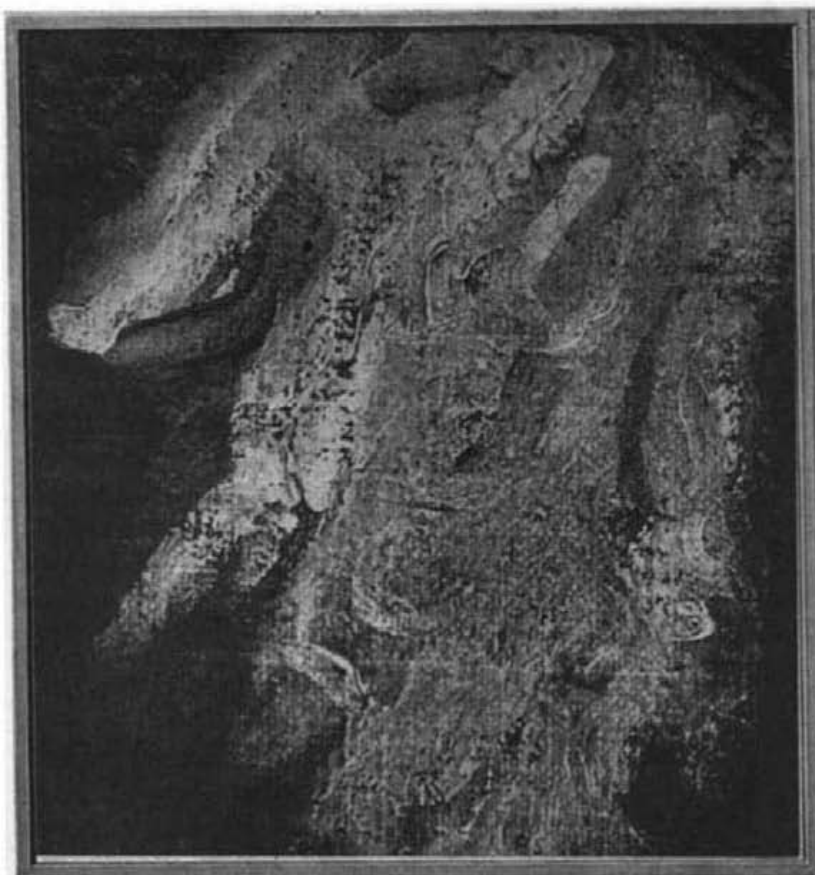

Fig. 7.-Brushwork of the "Spanish Admiral," which is attributed to Velasquez.

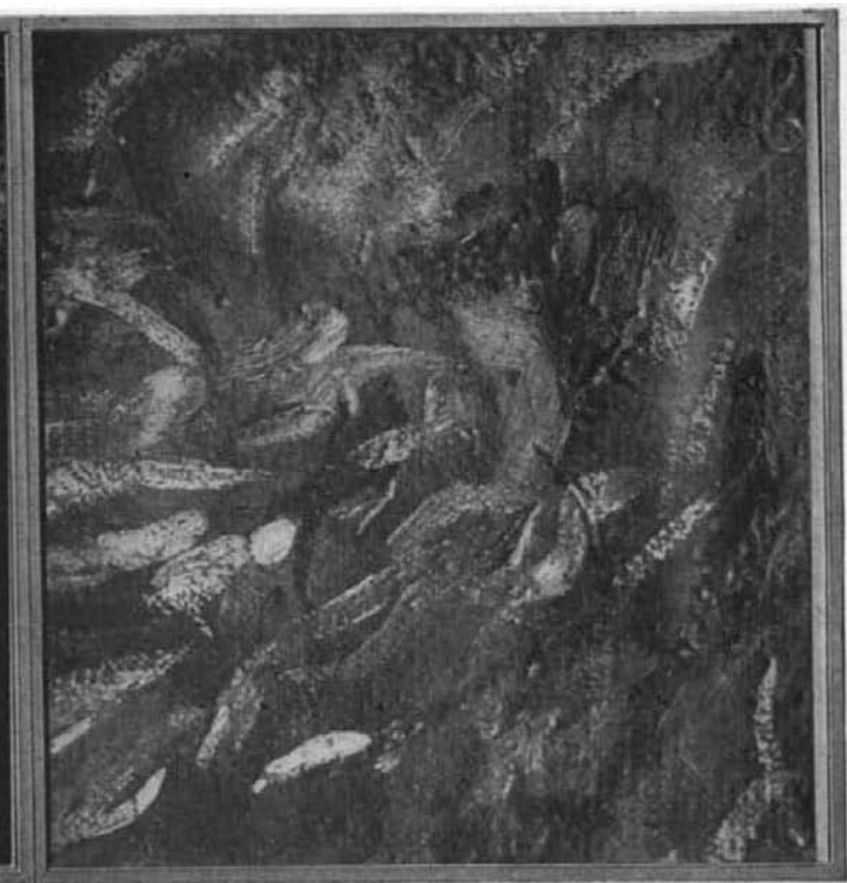

Fig. 8.-Brushwork in the portrait of Philip IV by Velasquez. man has his own way of laying on the paint which is characteristic.

During the time I have been investigating this method, I have been accumulating typical microphotographs of the brushwork of many of the great masters, and every day one is learning something new as to their methods, and also as to how far a man's brushwork varies, and how far certain characteristic touches remain throughout his career.

In the case of the painters of small pictures with minute figures, such as Teniers and Watteau, microphotographs of the whole of the face are usually most useful, and the enlargement may extend to five diameters on account of the minuteness of the brushwork employed by these artists. In the case of the life-size portrait painters, it is necessary to select some portion of the face into which the artist has put the greatest amount of careful work. On the whole, the eye usually gives the most information, magnified some three diameters. In the case of landscape artists, the painting of foliage is usualls very characteristic At the same time it is usually advisable to examine the picture very carefully with a view to seeing whether there is not some piece of rapid and characteristic painting on which the artist, working very freely, has shown his peculiar methods. In the case of Velasquez, for instance, it is often found in some portion of the painting of the figure itself-a piece of drapery or a tassel or a bit of embroidery being painted in with a rapid and characteristic hand.

There are also obviously certain dangers in an investigation of this kind, owing to the fact that so many of $\mathrm{the}$ great artists employed their pupils to do the less important parts of their $\mathrm{pa}$ in $\mathrm{ting}$, and therefore we must not be led astray by assuming the work of a pupil to be the work of a master. It is for this reason that, as a rule, it is safer to compare the more important parts of the painting.

From the large number of photographs which I have made, I select one or two typical examples, in order to illustrate the various points. The (Concluded on page 240.) 


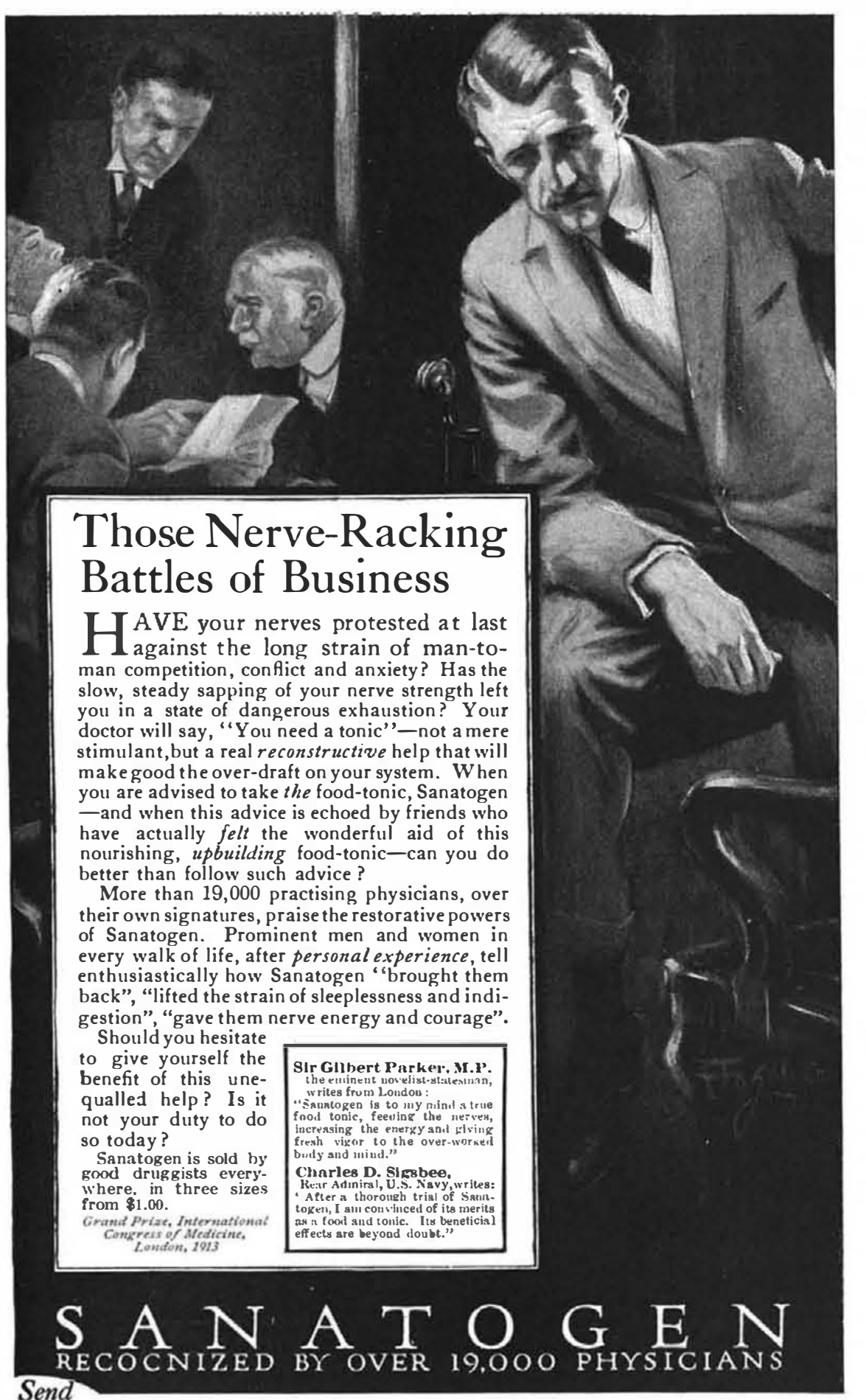

Send for Elbert Hubbard's new book- "Health in the Making." Written in his attractive manner and filled with his shrewd philosophy together with capital advice on
Sanatogen, health and contentment. It is free. Tear this off as a reminder to address THE BAUER CHEMICAL CO., 28-G Irving Place, New York.
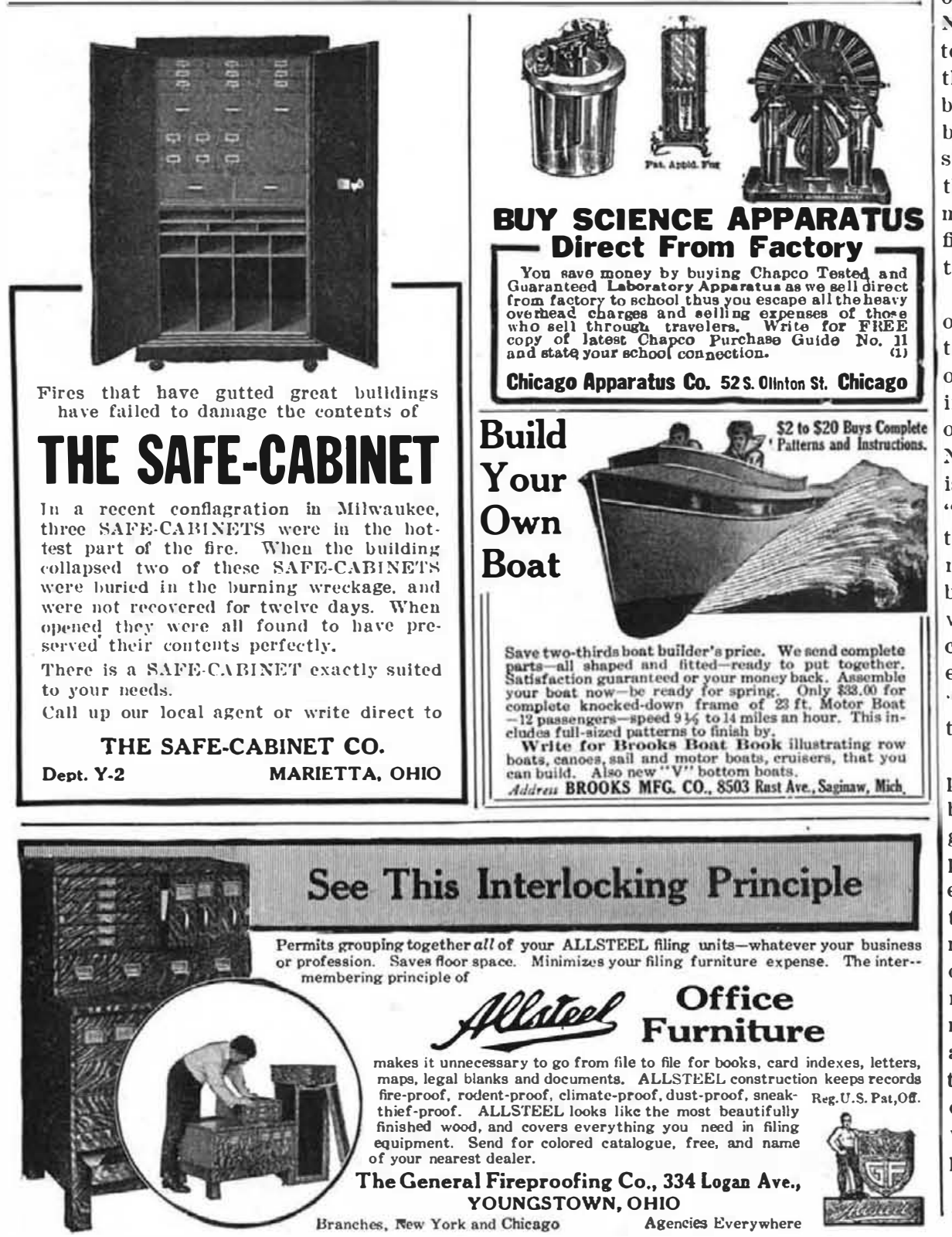

The Biggest of French Dirigibles (Concluded from page 232.)
incased and decked over like all of the car, which shows aiso general stream-
lines, and has a pretty, windowed observatory with a searchlight in its nose. A ma. chine gun is to protrude through a gun port in the side-rather an antiquated practice. The engine room in the center
contains auxiliary machinery - a ventilator for the ballonets, and dynamos for electric lighting and the wireless, of
the instruments are carried in the observa tory in the nose. The $A$ stra plant has also worked out an efticient system of swivel-
ing propellers, to be installed in their next leriathan. This plan has given great satisfaction on a small scale in Fngland, but as no force of men could handle a mammoth dirigible so efficiently and economically on the ground in landing and stat ing as 1,000 horse-power applied
swiveled propeller. Theoretically ould take a handling crew of 2,000 me to equal it.

Newest Way of Detecting Art Forgeries

first shows a microphotograph magnified some two and one half to three diameters
of one of the heads in the well-known of one of the heads in the well-known
Watteau in the Fdinburgh National Gallery. The second is the same head from a very careful copy by an accomplished is newer and shows the absence of cracks, it is very difficult to distinguish by the
ese from the original. This is clearly seen on comparing the photographs of the original and the copy. But the moment
that the microphotographs are compared the weakness and inferiority of the and also the want of delicate modeling in the drawing of the face and the ear. The third photograph is from the well-known Pater in the Edinburgh collection, and is of great interest as showing distinct re-
semblances to Watteau's methods, while, at the same time, the work is facile and shallow and wanting in the rich complexity and subtlety of the work of the The sixth photograph is from the head a man in the Teniers (No. 817) in the National Gallery, London, and is an interesting revelation of the brushwork of
this great artist. I may say that his brushwork is extraordinarily minute, it
being difficult to understand how he had sufficiently tine brushes to put in some of these tiny strokes, which it must be re membered are shown here highly magui-
fied and are therefore almost too fine for the eye to see in the original picture.
The next two photographs are example of the brushwork of Velasque\%, and illusrate the importance of seizing the work of the artist in a carelessly rapid paint ing mood. One is taken from the tasse
on the "Silver Portrait" of Philip in the National Gallery, London, and the other "The Spanish Admiral." Certain authori-
"Them the es have suggested that "The Spanish Admiral" is not by the hand of Velasque\%, but, while a larger number of photograph would be required for absolute proof, examples goes a long way to prove that "The Spanish Admiral" is by the hand o he great master.

Examples of the application of this process might be multiplied indefinitely aphs will be sufficient to illustrate the process. It must not be supposed, ho two photographs of a picture in order to ought to be carefully studied under the microscope with a view to examining for repainting, and dentifying the pigments
and mediums. Certain portions should and mediums. Certain portions should
then be selected as characteristic examples of brushwork, and these again compare very carefully with other pictures supwhole results of the investigation both b the microscope and camera considered to
LEGAL NOTICES

PATENTS

patent you can write fully and freely to Munn

metection. Please send sketches or a

device. explaining its operation.

All communications are strictly confidential. more than sixty years, enables us in period of advise in regard to patentability without any sent free on request. This explains our methods, terms. etc., in regard to PATENTS,
TRADE MARKS. FOREIGN PATENTS, etc. All patents secured through us are described
ithout cost to the patentee in the SCIENTIFIC MUNN Eg COMPANY 361 BROADWAY. NEW YORK Branch Office, $625 \mathrm{~F}$ Street. Washington. D. C.

Classified Advertisements

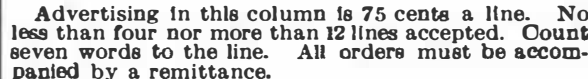
BusinEss OPPOR TUNITIES TO INVENTORS AND MANUFACTURERS
$\mathrm{n}$ old established English frm. with good connec-

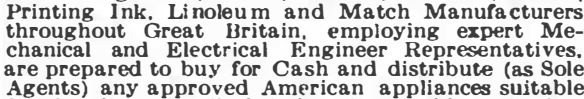

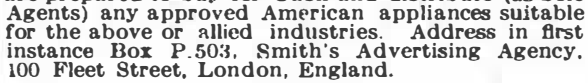
PATENTS FOR SALE PNEUMA TIC CLAMPING DEVICE for drill
press. Used by compressed air or manually. Can be
seen. worki ng at I. R. R. R. Shops. gell outright or
royalty. A. J. Sutch. 6409 Kenwood St., Chicago. III. SCIENTIFIC APPARATUS

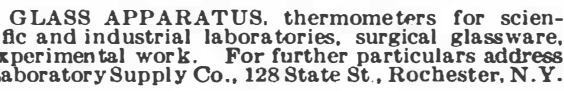
miscellaneous

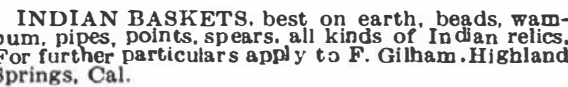
I N Q U I R I E S

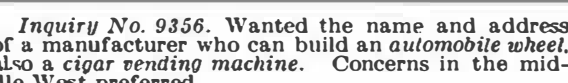
Inquiry No. 9357. Wanted the name and address
of a manufacturer of a machine for scalloped paper
a vors and cups. Inquiry No. 9358.- Wanted the name and address
maker of a machine to cut all granulate leather. Inquiry No. 9359. Wanted the name and address
of a thrm that makes razor blades for all makes of
safety razors.

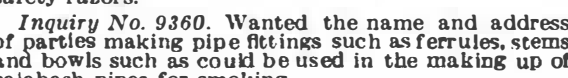
Inquir $\mathrm{Ne}$ o. 936!. Wanted to buy a Nut Crack-
ing Machine, especially good for Pecans. Inquiry No. 9362. Wanted the name and address
of the makers of a machine for splicing ties. Inquiry No. 9363 . Wanted the names and ad-
dresses of manufacturers of machinery for printing
on intaglio copper plates.

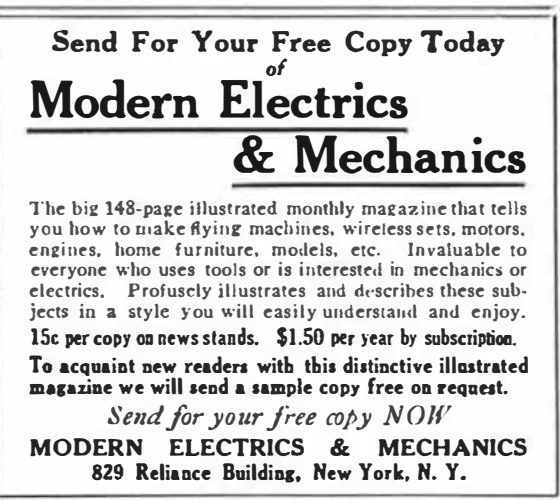
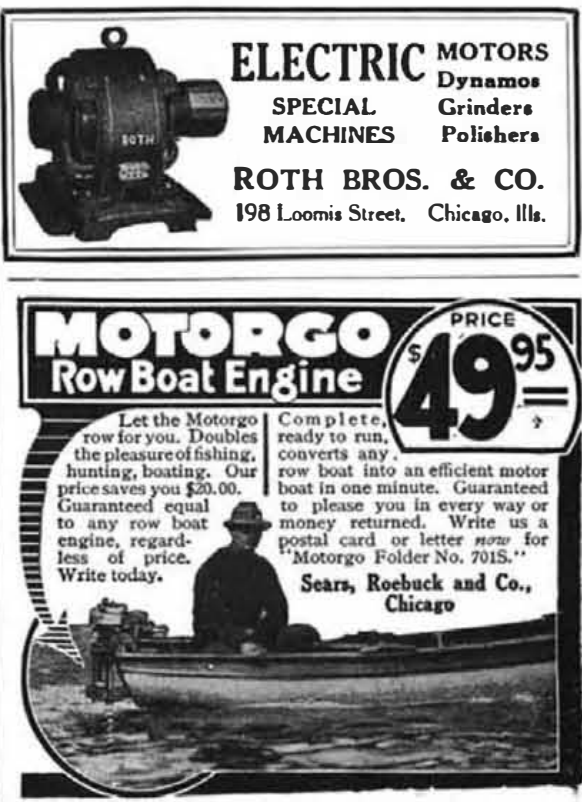


\section{Make It Easy to Try}

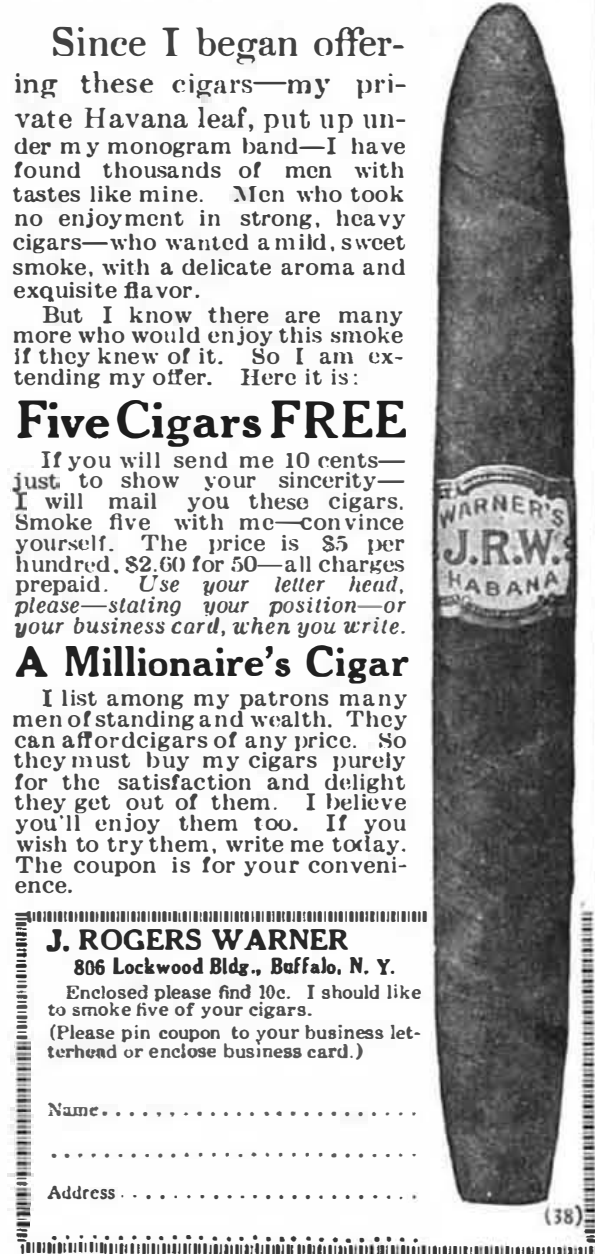

Your Earning Capacity

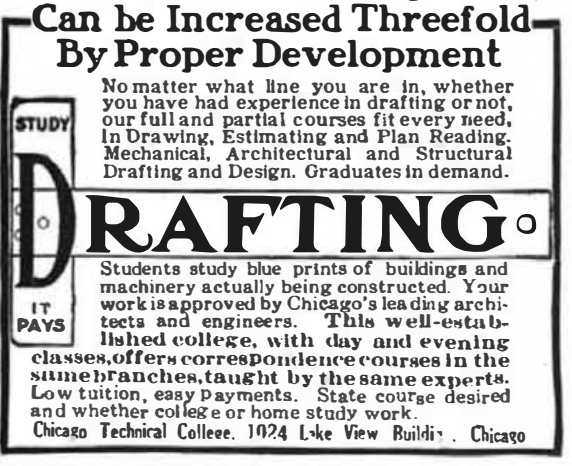
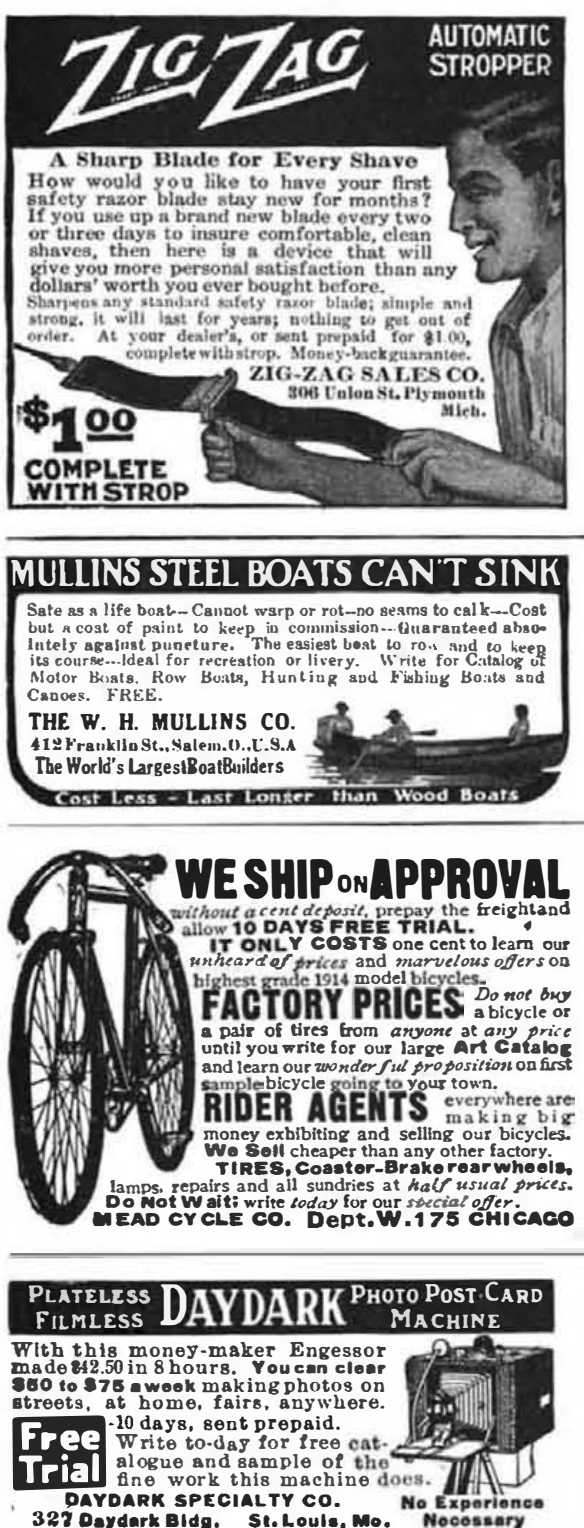

gether in coming to any final conclusion. sede the work of the art expert. His opinion on the authenticity of the picture re But they come in to assist him in his labors, to limit the problem that he has before him and to check by exact methods the conclusion at which he may have ar fer as to the origin of a picture, such methods go a long way to bringing the ample, 1 hat ve been lately tring to decide who is the original painter of "The Old Gres Hunter" in the National Gallery, London, ascribed to Paul Potter, and the results obtained are at present before $\mathrm{Dr}$. ture was by Verbeecı. I am also making a further inquiry into who is the painter of the portrait of Elizabeth laas in the collection at Amsterdam, 1nr. Irredius halving suggested that it is probably by Bol, and not kembrandt.

The Tunnel Under the English Channel

THE question of the tumnel under the Tinglish Chamel is quite the order of the day in the two countries interested, and especially among persons who are occupied with engineering and economic questions. some interesting points abou the proposed great work were set forth chool and chief engineer of the North Railway, in a recent conference on the subject. From an economic standpoint enormous increase in passenger and al kinds of tratfic, and will be a source of mrosperity to England, France and other nations. Capital will be easy to raise in
both comntries, and the cost is not expected exceed $\$ \$ 0,000,000$. Technical difficultie prear to be less than for such mountain ork as the Simplon tumnel and other: prise is to work in the impermeable green chello ind parallel tunnels, with a railroad track in each tumnel. Military preoccupations hase Sugland in view of the good relations be Ween the two countries, and it is consid to ideas of peace and concord. The main of the realization of the project from the traditionalism which preails in England, as it is held that the success and special qualities of the race largely come from the insular position of the other hand that such an idea does not fit into modern progress and that in the course of time it will lose its force, so ried out at a not very distant date.

Earthquakes and Changes of Latitude:

A s long ago as 1903 I'rof. Milne called to an apparent connection between displacements of the terrestrial poles and earthquakes. Ile found that in rear's when pole-displacements have been
relatively large, world-shaking earthquakes have been numerous, and vice versa. Milne did not believe that the molar displacement represented by these polar change but thought that both might result from a common cause. This subject matically by been investigated matheeral conclusion is that the rapid axial displacement is the primary phenomenon and the earthquake secondars.

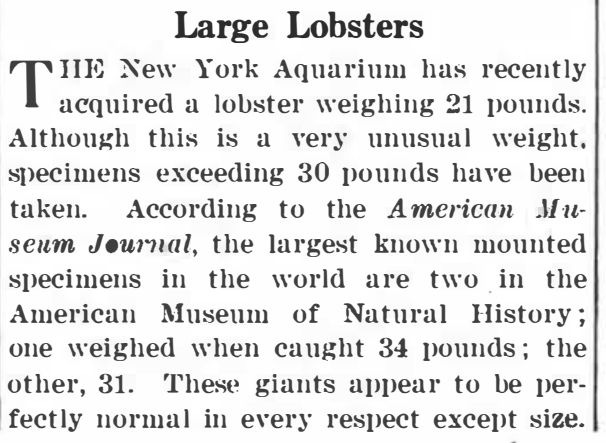

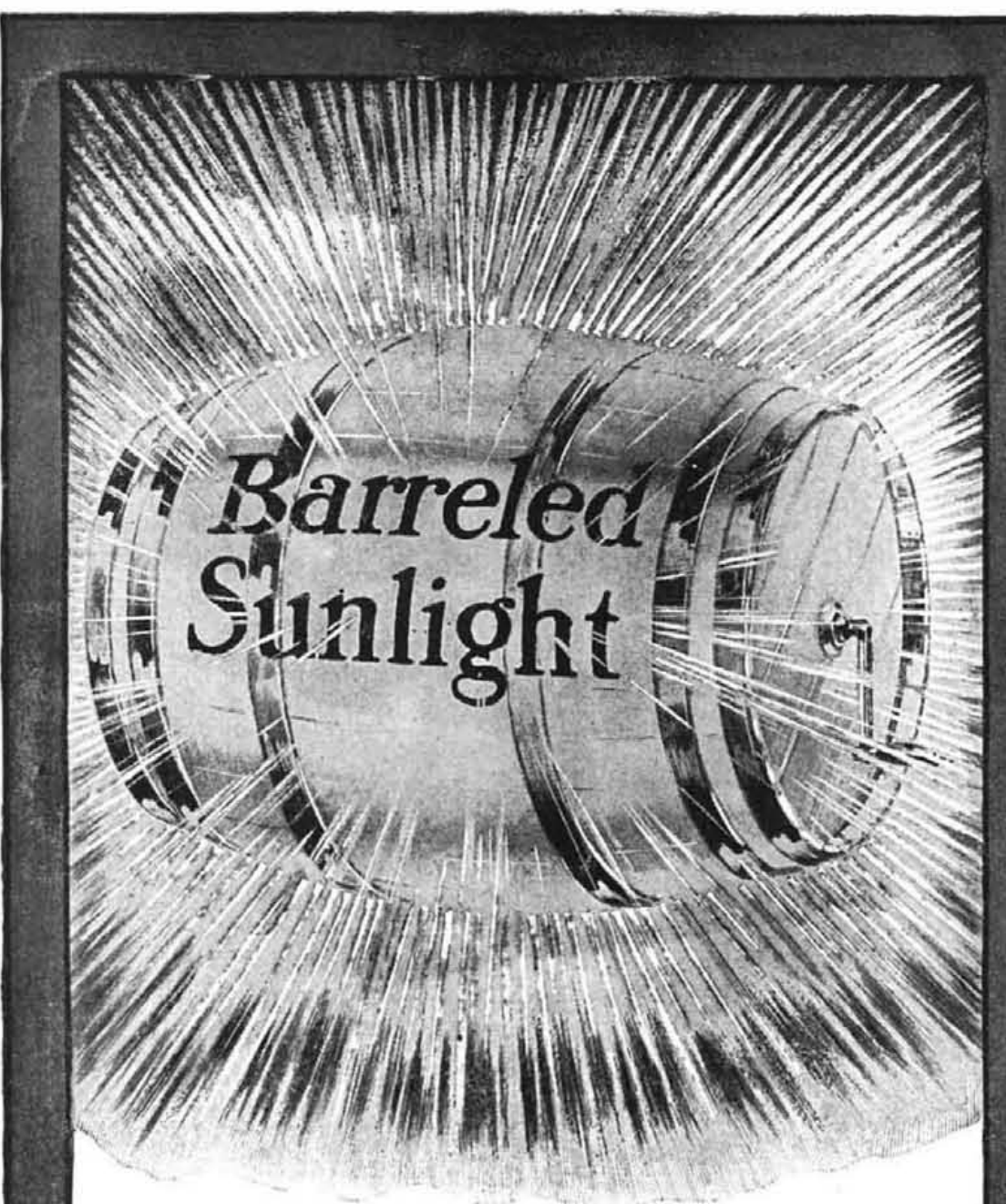

TF you could buy a barrel of anything 1 which would increase the light in your factory 19 to 36 per cent, wouldn't you seriously consider its purchase?

That is a fanciful way of putting our proposition, but it is all fact, nevertheless. 19 to 36 per cent actual increase in light (depending on the present condition of your ceilings and walls) is what you will gain, if you paint the interior of your factory with

\section{RICE'S MILL WHITE}

The only oil paint (without varnish) giving a glossy, tile-like finish

Rice's Mill White will fill your factory with sunshine. It will reflect every ray of sour natural or artificial light down on your machinery and into the dark corners of your plant. Its glossy like a flat paint. It can be washed like tile.

Rice's Mill White will not scale and require frequent renewals like a cold-water paint. It will not "alligator" and crack under the jar of machiners like a varnish paint. It flows easily It stalys whitc longer than any other gloss paint.

\section{The Original Mill White}

Rice's Mill White made a trade name of the words, "Mill White" None of its imitations has its elastic, permanent qualities. No other paint manufacturer can use the Rice process. for illuminating poure, sanifary qualities and low ultimate cost.

\begin{tabular}{|c|}
\hline Rice's Granolith \\
\hline 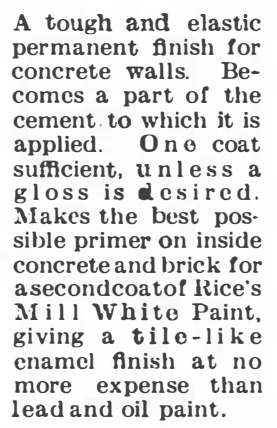 \\
\hline $\begin{array}{l}\text { For Concrete } \\
\text { Surfaces }\end{array}$ \\
\hline
\end{tabular}

Rice's Mill White is sold direct from our factory, in barrels containing suf fient paint to cover 20,000 square feet, one coat. If you have that area

Write for Booklet and Sample Board

Ask for a copy of our booklet,

"More Iight." Write torlay.

U. S. GUTTA PERCHA PAINT CO.

23 DUDLEY STREET
PROVIDENCE, R. 1. 